\title{
Impact of Educational Program on Nursing Care for Children Suffering from Wilms' Tumor
}

\author{
Ebtesam Ahmed Abd Elsamea Soliman1, Sabah Saad Al-Sharkawi2, Alaa Abd El.Hamed \\ Younes3, Faten Shafik Mahmoud4 \\ 1 Pediatric Nursing, Technical Healthy Institute, 2 Pediatric Nursing, Faculty of Nursing Ain Shams \\ University, 3 Surgical Oncology National Cancer Institute Cairo University, 4 Pediatric Nursing, Faculty \\ of Nursing Benha University
}

\begin{abstract}
Aim: This study aimed to assess the impact of an educational program on nurses' knowledge and performance regarding nursing care of children with WT. Setting: This study was conducted at the outpatient and inpatient of pediatric oncology departments in Children Cancer Hospital (57357). This study sample is convenient, involved all the available (60) staff nurses giving nursing care for about 70 children suffering from WT. Tools of data collection included a structured interviewing questionnaire and Observational checklists sheets for assessing nurses' knowledge and performance (pre-posttest and follow up). The findings of the present study revealed that, the impact of the educational program on nurses' knowledge and performance about care of children with WT the result concluded that there was a positive correlation between nurses' knowledge and performance regarding WT after the educational program implementation. The result recommended that newly appointed nurses who are working at oncology unit must have an orientation program prior to care of children with Wilms' tumor, periodical continuous on job-training programs for oncology nurses to update and refresh their knowledge and performance about care of children with Wilms' tumor, regular clinical sessions to monitor the nursing performance at 57357 hospital will reinforce and improve the skills regarding to care of children with Wilms' tumor and further studies and replication of this study in other oncology units.
\end{abstract}

Key words: Wilms' Tumor, children, chemotherapy, radiotherapy, surgery and port a cath into a malignant, or cancerous mass

\section{Introduction}

Wilms' tumor (WT) or nephroblastoma is the most common primary renal malignancy of childhood. Worldwide Wilms' tumor account for $90 \%$ of pediatric renal tumor which represents $6 \%$ of childhood cancer, it occurs in about 1 out of 200,000 to 250,000 children, and it strikes when a child is about 3 years old. It's occur when certain cells in one or both kidneys multiply uncontrollably, growing
(Malkan et al., 2015).

The nurse plays a major role in caring for children with Wilms' tumor through preparing the children and their family for diagnostic and therapeutic procedures, in postoperative period the nurse observing the surgical incision for erythema, drainage or separation and they provide emotional support for children and their parents to assist them in coping with the disease. Moreover, nurses caring for patients receiving chemotherapy require specialized 
knowledge in order to ensure safety for both patients life and for their own safety of the jobs (Oberoi et al., 2016).

Educational program about Wilms' tumor and its management qualify nurses to assess children in a continuous process throughout the treatment and follow up. Meanwhile, nurses are the most important person that can detect the toxicity of chemotherapy and radiotherapy, so the educational program is very beneficial icon to avoid theses side effects of the treatment (Grundy, et al., 2010).

\section{Importance of the study:}

Worldwide about $90 \%$ of kidney cancers found in children is wilms' tumors. Wilms' tumors usually only affect one kidney (unilateral) but in about 7 out of every 100 children (7\%) it can affect both. According to El-Gharbia population based cancer registry (the only available population based cancer registry in Egypt), the percentage of wilms' tumor in children with kidney cancer is about 94\%. At children's Cancer Hospital in Egypt, about, 375 new cases of wilms' tumor presented to the hospital from 7/7/2007 till 31/12/2012 (with an average 70 patients each year). (Vanderpool, 2011 \& Children's Cancer Hospital, 2013). In addition, nurses need advanced knowledge and practice in caring those children, so the educational program for oncology nurses for provide competent nursing caring to children with Wilms' tumor is important to know how to deal with this disease, side effect of chemotherapy and how to prevent the complications of the disease and the types of treatment.

\section{Aim of study}

The aim of this study is to assess the impact of the educational program on nurses' knowledge and performance about care of children with wilms' tumor through:
- Assess, design and implement an educational program.

- Evaluate the effect of educational program on nursing care given for children having wilms' tumor.

\section{Research Hypothesis:}

After attending the educational program, nurses will improve in their knowledge and performance regarding care of children suffering from Wilms' tumor.

\section{Subject and Methods:}

The present study conducted with the aim of study is to assess the impact of the educational program on nurses' knowledge and performance about care of children with Wilms' tumor (WT).

Research design a quasiexperimental design:

Technical design, includes research settings, subjects and tools of data collection.

Settings, was carried out at the outpatient and inpatient Pediatric Oncology Departments in Children Cancer Hospital Egypt (57357).

Subjects of study: involved (60) nurses from both genders, had nursing degree and delivered the nursing care for about 70 children suffering from Wilms' tumor.

Tools and technique of data collection: data was collected by using the following tools:

Tool (1): A structure Interview Question-naire Sheet (pre-post-test):

It was developed by the researcher in the light of relevant studies and researches and guidance of supervisors. It was written 
in an Arabic language and composed of two parts, to collect the following data:

Part (1): Nurses' Characteristics: as age, gender, educational level and years of experience, course training.

\section{Part (2): Nurses' knowledge}

about Wilms' tumor, the nurses' knowledge about Wilms' tumor includes (information about Wilms' tumor as definition and stages, diagnosis and clinical manifestations, types of treatment, (surgical treatment, chemotherapy treatment and it's side effects and radiotherapy treatment), Wilms' tumor complications, pre and post-operative nursing intervention, follow-up and health education.

\section{Scoring system of knowledge:}

All knowledge were weighted upon completion of the interview questionnaire where the studied subject's knowledge was checked with a model key answer and accordingly their knowledge was scored as:

$$
\text { Good equal } 80 \text { to } 100 \%
$$

Poor equal 0 to $<80 \%$

\section{Tool (2): An Observational} Checklists: to assess nurses' performance about care of Wilms' tumor, it adopted from children's cancer hospital in Egypt (57357)، four procedures were included in the checklist; (nasogastric tube insertion, wound dressing, administration of chemotherapy and IV infusion-port)

- Nasogastric tube procedure consisted of 9 steps, each correct step scored 1 to make a total score of (9).

- Wound dressing procedure (Policy and Procedure of the Children's Cancer Hospital, 57357) consisted of 15 steps, each correct step scored 1 to make a total score of (15).
- Administration of chemotherapy procedure consisted of 30 steps, each correct step scored 1 to make a total score of (30).

- IV infusion -port consisted of 18 steps, each correct step scored 1 to make a total score of (18).

\section{Scoring system of practice:}

All practice related items were scored as (0) for not done correctly and (1) for done. Total practice score equal 72 score equal to $100 \%$

Total practice score was classified as the following:

- Competent: $\geq 90 \%$ of total practice score.(58-72)

- Incompetent: < $90 \%$ of total practice score. $(0-57)$

\section{Tool validity:}

Content validity was checked before the pilot study and the actual data collection through distribution of the tools to five expertise in the field of the study (medical and nursing staff) from the Children's Cancer Hospital in Egypt (57357) who were recommended by the Scientific Medical Advisory Committee (SMAC) of the Children's Cancer Hospital in Egypt (57357), with a covering letter and an explanation sheet that explained the study's aim and other related information to ensure appropriateness, relevance, clarity and completeness of the tool.

\section{Operational Design:}

Preparatory Phase: the researcher reviewed the local and international related literature and studies covering various aspects of the research problem to get acquainted with the research problem and to develop the study tools. 


\section{Pilot Study:}

The pilot study was conducted on 10 $\%$ of the study's subject (6 nurses) to evaluate the applicability, efficiency and reliability of the tools that used .Results of the pilot study helped in necessary modification of the used tools. All participants in the pilot study were included in the study subjects, where no radical modification was carried out in the study tools as revealed from the pilot.

\section{Field Work:}

The study was carried out from the first September 2014 to the end of April 2015 at the Outpatient and Inpatient Pediatric Oncology Departments in Children's Cancer Hospital Egypt (57357). The researchers used a structure interview questionnaire sheet as pretest. The educational program were prepared in the light of the actual needs assessment of the studied nurses. The educational sessions introduced through PowerPoint presentations, asking questions and group discussion. Then post-test conducted immediately post program implementation and at follow up three months after program implementation. The researchers used an observational checklist to measure the nurses' performance about Wilms' tumor. The researcher developed a schedule and time frame for studied nurses that appropriate with their work time.

Studied nurses divided into 6 groups (10 nurses each) then each group was gathered at the conference room or training room separately for about 30 minutes. During this meeting the researchers; explain the purpose of the study and disseminated each nurse handout includes all contents of knowledge and procedures steps to facilitate remembers steps about care of pediatric patients with Wilms' tumor The check lists include five items (cannula insertion, nasogastric tube, wound dressing, administration of chemotherapy and IV infusion -port). The program was presented in clear and concise form using different teaching methods as lectures, demonstration and re- demonstration.

The nurses were instructed to observe the researcher carefully during demonstration the procedures because every one of them demonstrated the procedure in front of the researcher and they will be evaluated by the researcher. The researcher demonstrated all the procedure' steps on pediatric patient in front of the nurses. At the end of the researcher's demonstration, nurses were asked about any unclear steps which needed repetitions or explanation before redemonstration. Each nurse observed after implementation of the program, the nurses' evaluation was done using the same technique and the same tools after 3 months.

The nurse's performance in cannula insertion was competent in pretest, so it excluded from the program. In the other side, the nurses scored incompetent performance in the other procedures in the pre-test so these procedures involved in the program and post-test. The researchers observed the nurses' performance in the pediatric patient areas in the post-test.

\section{The Educational Program:}

It was designed by the researcher according to actual needs assessment of the study subject after review of the related literature.

\section{First Phase:}

A pretest was carried out by using the previously mentioned tools to assess nurses' knowledge and performance for children with Wilms' tumor. 


\section{Second Phase:}

His phase included analysis of the pre-test findings and identification of the actual nurses' needs toward Wilms' tumor. Accordingly, the guide intervention (Hand out) was designed by the researchers, using simple Arabic language and different illustrated figures as kidney anatomy, stages of Wilms' tumor clinical manifestations figure and port a cath figure in order to facilitate subjects understanding.

\section{Third Phase (Planning and Implementat-ion):}

General and specific objectives of educational program were stated and implemented to achieve the aim of the study. The educational program was carried out in 10 sessions, the total No. of sessions related knowledge of Wilms' tumor were 6 sessions while total No. of sessions related practice were 4 sessions. The time of the sessions were ranged from 30-90 minutes according to the objectives of the session. The educational program was implemented for each group for three weeks (4 days/week), different teaching methodology were used as lectures, group discussion, demonstration and redemonstration.

Evaluation was carried out immediately after the implementation of the educational program by using the same pretest format for knowledge and the same checklists for nurses' performance as a post test.

\section{Fourth Phase:}

Follow up of the educational program was executed after 3 months by using the same pre \& post test tools (questionnaire and checklist).

\section{Administrative Design:}

An official approval was obtained from the administrators of the study settings to carry out the study. A clear explanation was given about the nature, importance and expected outcomes of the study.

\section{Ethical Considerations:}

Aim, nature and expected outcomes of the research were explained to the study subjects before their inclusion. The study subjects were informed that, the study is harmless and all the gathered data was used for research purpose only. An oral consent was obtained from each subject to participate in the study. Anonymity and confidentiality were secured and ensured that they have the right to withdraw from the study.

\section{Statistical Design:}

The collected data were organized, tabulated and analyzed using electronic computer and statistical package for social sciences (SPSS) version11. General characteristics of the nurses were presented in terms No. of percentage, mean and standard deviation and $t$ test was used to examine the relationship between pre, post and follow up educational intervention for knowledge, r. was used to examine the correlation, $\mathrm{X}^{2}$ was used to examine the relationship between pre, post and follow up educational intervention for practice and chi-square test was used to study the relation between socio-demographic data and total knowledge and performance scores.

\section{Results}

Table (1) illustrates the characteristics of the studied nurses, the mean $\pm \mathrm{SD}$ age of them is $26.05 \pm 2.16$ years, $51.7 \%$ of them were female, and $100 \%$ of 
them had an orientation training courses. The mean \pm SD years of experience of them is $5.78 \pm 4.74$

Table (2) this table revealed that there was a highly statistically significant differences among studied nurses' knowledge mean score at pre, immediate post and follow up phases of implementation regarding knowledge related to WT, diagnostic of WT, types of treatment of WT, treatment with chemotherapy, treatment with radiotherapy, complications of WT, nursing implementation for surgical operation, follow up for WT and health education about WT. $\left(\mathrm{p}<0.001^{* *}\right)$.

Figure (1): illustrated the distribution of total knowledge score of the studied nurses regarding to Wilms' tumor at the different phases of program implementation, it was revealed that there was highly statistically significant difference among studied nurses' knowledge mean score pre, immediate post and at follow up phases of program intervention regarding to Wilms' tumor. The total knowledge score of the nurses regarding Wilms' tumor at the different phases of the program revealed that $(86.7 \%)$ of nurses' scores was poor and $(13.3 \%)$ of nurses scores was good preprogram. Immediate post program $(88.3 \%)$ of nurses scores good, and (11.7\%) was poor. Three months' after the program $(83.3 \%)$ of nurses was good knowledge and (16.7\%) was poor.

Table (3) this table shows distribution of the studied nurses' performance regarding to port a cath needle insertion for children with Wilms' tumor at different phases of program implementation., it was found that the majority $(95.0 \%$ and $88.3 \%)$ of the studied nurses had competent performance regarding to ensure right patient identification, check for any notification of medication allergies/adverse reactions, flash port with $10 \mathrm{ml}$ normal saline using $10 \mathrm{Ml}$ syringe, connect the medication into the port with the aseptic technique and documentation the patient's response to the medication, time and route of administration and side effect respectively post program implementation compared to $18.3 \%, 21.7 \%, 36.7 \%, 36.7 \%$ and $28.3 \%$ respectively preprogram implementation. These differences were statistically significant pre and post intervention program, ( $\mathrm{X}^{2} 1$ : 71.81, 66.37, 34.16, 34.16 and 44.43 at $\left.\mathrm{p}<0.001^{* *}\right)$. This table also illustrated that there was statistical significance differences between post and follow up $\left(X^{2} 2\right.$ : 59.06, 59.86, 29.41, 27.22 and 36.80 at $\mathrm{p}<0.001 * *)$.

Figure (2) illustrated that the majority of nurses $(95 \%$ and $91.7 \%$ ) had competent performance regarding to care of children with Wilms' tumor respectively immediately after and at follow up phase compared to $21.7 \%$ preprogram implementation.

Table (4) shows the correlation between studied nurses' total knowledge and their performance regarding to Wilms' tumor score at different phases of program implementation, it revealed that there was a positive correlation between total knowledge and performance score at pre, immediate post and follow up phase of program implementation.

Table (5) shows the correlation between studied nurses' total knowledge score with their age, years of experience and level of education at pre, immediate post and follow up phase' of program implementation. It revealed that there was a positive correlation between total knowledge with age and years of experience at the pre-implementation phase $(\mathrm{P}=>0.05)$.

Table (6) illustrated the correlation between studied nurses' total performance score with age, years of experience and 
educational level at different phases of program implementation at different phases of program implementation, it revealed that there was a positive correlation between total performance and level of education at the pre-implementation phase $(\mathrm{P}=.>0.05)$.

Table (1): Characteristics of the studied nurses $(n=60)$.

\begin{tabular}{|l|c|c|}
\hline \multicolumn{1}{|c|}{ Variable } & No & $\%$ \\
\hline Age in years & 19 & 31.7 \\
\hline $20-<25$ & 26 & 43.3 \\
\hline $25-<30$ & 14 & 23.3 \\
\hline $30-<35$ & 1 & 1.7 \\
\hline$\geq 35$ & \multicolumn{2}{|c|}{$26.05 \pm 2.16$} \\
\hline Mean \pm SD & \multicolumn{2}{c|}{} \\
\hline Gender & 31 & 51.7 \\
\hline Male & 29 & 48.3 \\
\hline Female & \multicolumn{2}{|c|}{} \\
\hline Educational qualification & 26 & 43.3 \\
\hline Secondary nursing education & 5 & 8.3 \\
\hline Technical nursing education & 27 & 45.1 \\
\hline Baccular of nursing & 2 & 3.3 \\
\hline Secondary nursing education + specialty & & \\
\hline Years of experience & 26 & 43.3 \\
\hline $1-$ & 19 & 31.7 \\
\hline $5-$ & 15 & 25.0 \\
\hline $10-$ & & \\
\hline$\geq 15$ & & $5.78 \pm 4.74$ \\
\hline Mean \pm SD & 0 & 100 \\
\hline Orientation courses training & 60 & \\
\hline No & & \\
\hline Yes & & \\
\hline
\end{tabular}


Table (2): The studied nurses' mean score regarding their knowledge about Wilms' tumor in children pre, post and at follow up of educational program implementation $(n=60)$.

\begin{tabular}{|c|c|c|c|c|c|c|c|c|c|c|}
\hline \multicolumn{2}{|c|}{5} & $\frac{7}{\frac{7}{8}}$ & $\begin{array}{l}\frac{*}{8} \\
\frac{7}{8}\end{array}$ & $\stackrel{4}{\frac{7}{8}}$ & $\begin{array}{l}\frac{*}{8} \\
\frac{8}{8}\end{array}$ & 䓪 & 草 & $\frac{7}{\frac{7}{8}}$ & $\frac{7}{8}$ & $\begin{array}{l}\frac{7}{8} \\
\frac{7}{8}\end{array}$ \\
\hline \multicolumn{2}{|c|}{ 常 } & 芯 & $\frac{9}{7}$ & $\overline{8}$ & $\begin{array}{l}\text { 朚 } \\
\text { 学 }\end{array}$ & $\frac{9}{7}$ & 齐 & 을 & 嚍 & 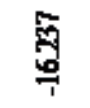 \\
\hline \multicolumn{2}{|c|}{5} & $\begin{array}{l}\stackrel{*}{8} \\
\frac{8}{7}\end{array}$ & $\frac{7}{8}$ & $\begin{array}{l}\frac{*}{5} \\
\frac{8}{7}\end{array}$ & $\frac{\text { 营 }}{8}$ & $\frac{4}{8}$ & 草 & $\begin{array}{l}\text { 䓪 } \\
\text { 品 }\end{array}$ & $\begin{array}{l}\stackrel{*}{8} \\
\frac{8}{8}\end{array}$ & $\begin{array}{l}\frac{*}{8} \\
\frac{8}{7}\end{array}$ \\
\hline \multicolumn{2}{|c|}{ 龺晋 } & $\frac{5}{9}$ & $\frac{9}{9}$ & তี & 象 & 承 & 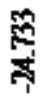 & 管 & $\frac{\text { gू }}{\frac{7}{4}}$ & 葛 \\
\hline \multirow{3}{*}{5} & 完 & 声 & 桑 & 客 & 总 & 춱 & 욤 & 兽 & 莺 & $\frac{8}{8}$ \\
\hline & +1 & +1 & +1 & +1 & +1 & +1 & +1 & +1 & +1 & +1 \\
\hline & 8 & 8 & $\stackrel{9}{3}$ & 営 & 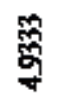 & है & m & $m$ & 8 & 8 \\
\hline \multirow{3}{*}{ 营 } & 完 & 兴 & 옹 & 哂 & 胥 & 곡 & 㝵 & 8 & 等 & 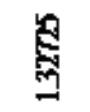 \\
\hline & +1 & +1 & $H$ & +1 & +1 & +1 & +1 & +1 & +1 & $H$ \\
\hline & 8 & 8 & 8 & 舜 & $\frac{\sqrt{n}}{n^{\prime}}$ & 흥 & 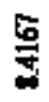 & \% & 骨 & 8 \\
\hline \multirow{3}{*}{. } & 完 & 콜 & 온 & 宓 & $\overline{2}$ & 읍 & 密 & 8 & 桑 & 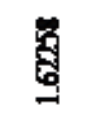 \\
\hline & +1 & +1 & +1 & +1 & +1 & +1 & +1 & +1 & +1 & $H$ \\
\hline & 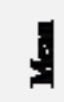 & 8 & 骨 & m & $\frac{5}{9}$ & m & 8 & m & 8 & $\underset{8}{8}$ \\
\hline & 8 & 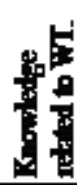 & 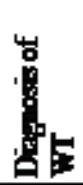 & 岁岩 & & & & 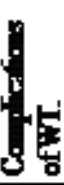 & $\begin{array}{l}5 \\
0 \\
0 \\
0\end{array}$ & $\begin{array}{r}8 \\
8 \\
8 \\
8 \\
8 \\
8\end{array}$ \\
\hline
\end{tabular}


Figure (1): Distribution of total knowledge score of the studied nurses regarding to Wilms' tumor at the different phases of program implementation.

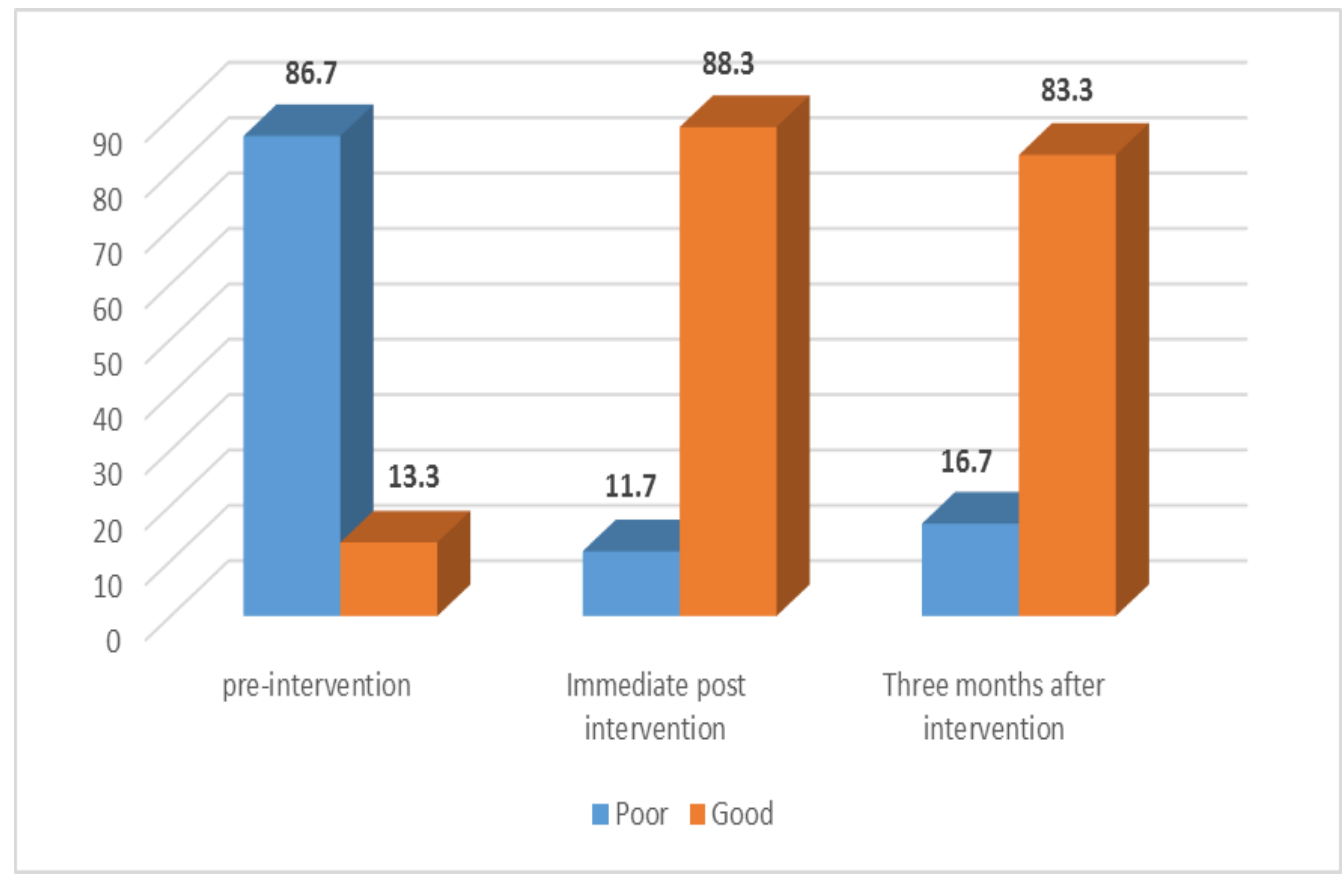


Table (3): The studied nurses' performance regarding to port a cath needle insertion for children with Wilms' tumor at different phases of program implementation.

\begin{tabular}{|c|c|c|c|c|c|c|c|c|c|c|c|c|c|c|c|c|}
\hline \multirow{4}{*}{$\begin{array}{c}\text { Procelure ef } \\
\text { Fut a coth needle } \\
\text { insedin }\end{array}$} & \multicolumn{12}{|c|}{ 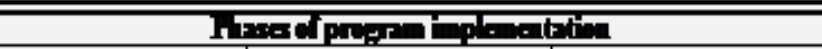 } & \multirow{4}{*}{ 氝 } & \multirow{4}{*}{ Prihe } & \multirow{4}{*}{ 约 } & \multirow{4}{*}{$\underset{\text { vine }}{\mathbf{P}}$} \\
\hline & \multicolumn{4}{|c|}{$\begin{array}{c}\text { Tro } \\
\text { inplontion }\end{array}$} & \multicolumn{4}{|c|}{ Implotepent } & \multicolumn{4}{|c|}{ 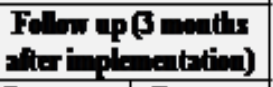 } & & & & \\
\hline & \multicolumn{2}{|c|}{$\begin{array}{c}\text { Inowpet } \\
\text { at }\end{array}$} & \multicolumn{2}{|c|}{$\begin{array}{c}\text { Conpe } \\
\text { teit }\end{array}$} & \multicolumn{2}{|c|}{ Inosentent } & \multicolumn{2}{|c|}{\begin{tabular}{|c|} 
Conpete \\
nt
\end{tabular}} & \multicolumn{2}{|c|}{\begin{tabular}{|c|} 
Inconpet \\
at
\end{tabular}} & \multicolumn{2}{|c|}{$\begin{array}{c}\text { Conpet } \\
\text { nt }\end{array}$} & & & & \\
\hline & No & $\%$ & No & $\%$ & No & $\%$ & No & \% & No & $\%$ & No & \% & & & & \\
\hline 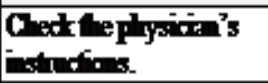 & 49 & $\$ 1.7$ & 11 & 18. & 9 & 15.0 & 51 & 25.0 & 12 & 20.0 & 48 & $\mathbf{m 0}$ & $\begin{array}{c}533 \\
9\end{array}$ & $\underset{*}{0.001^{*}}$ & 45.64 & $* 0.01$ \\
\hline 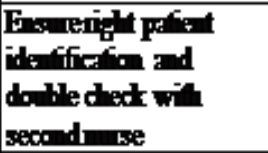 & 49 & 81.7 & 11 & 18. & 3 & 5.0 & 57 & 95.0 & 7 & 11.7 & 53 & $\mathbf{4 3}$ & $\begin{array}{c}71.8 \\
1\end{array}$ & $\underset{*}{0.001^{*}}$ & 59.06 & $=0.001$ \\
\hline 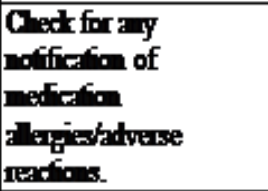 & 47 & 73 & 13 & 21. & 3 & 5.0 & 57 & 95.0 & 5 & 83 & 55 & 91.7 & $\begin{array}{c}663 \\
7\end{array}$ & $\underset{*}{0.001^{*}}$ & 59.86 & $=0.001$ \\
\hline $\begin{array}{l}\text { Wathlyds and wea } \\
\text { stile foves. }\end{array}$ & 43 & 71.7 & 17 & $\begin{array}{c}22 \\
3\end{array}$ & 10 & 16.7 & 50 & 833 & 13 & 21.7 & 47 & 723 & $\begin{array}{c}36.8 \\
0\end{array}$ & $\underset{*}{0.001^{*}}$ & 30.13 & +0.001 \\
\hline 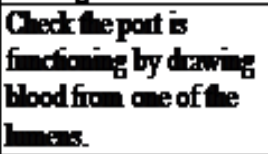 & 47 & 73 & 13 & 21. & $\mathbf{8}$ & 133 & 52 & 86.7 & 11 & 183 & 49 & 81.7 & $\begin{array}{c}51.0 \\
5\end{array}$ & $\underset{*}{0.001^{*}}$ & 4324 & $=0.001$ \\
\hline 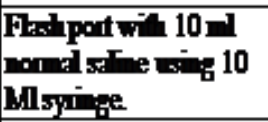 & 38 & 633 & $\mathbf{2 2}$ & $\begin{array}{l}36 \\
7\end{array}$ & 7 & 11.7 & 53 & $2: 3$ & 9 & 15.0 & 51 & 85.0 & $\begin{array}{c}34.1 \\
6\end{array}$ & $\underset{*}{-0.001^{*}}$ & 29.41 & $=0.001$ \\
\hline 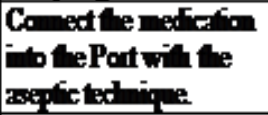 & 38 & 633 & 22 & $\begin{array}{l}36 \\
7\end{array}$ & 7 & 11.7 & 53 & at3 & 10 & 16.7 & 50 & 833 & $\begin{array}{c}34.1 \\
6\end{array}$ & $\underset{*}{-0.001^{*}}$ & 2722 & $=0.001$ \\
\hline 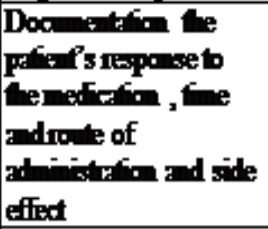 & 43 & 71.7 & 17 & 24. & 7 & 11.7 & 53 & 283 & 10 & 16.7 & 50 & 833 & $\begin{array}{c}44.4 \\
3\end{array}$ & $\underset{*}{-0.001^{*}}$ & 36.20 & $=0.001$ \\
\hline 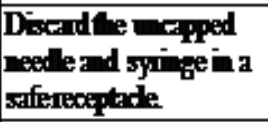 & 39 & 65.0 & 21 & $\begin{array}{c}35 . \\
0\end{array}$ & 16 & 26.7 & 44 & 733 & 17 & 283 & 43 & 71.7 & $\begin{array}{c}17.7 \\
5\end{array}$ & $\underset{*}{-0.001^{*}}$ & 16.20 & $=0.001$ \\
\hline Renvegres and & 31 & 51.7 & 29 & $\begin{array}{c}48 \\
3\end{array}$ & 8 & 133 & 52 & 86.7 & 9 & 15.0 & 51 & 85.0 & $\begin{array}{c}20.0 \\
9\end{array}$ & $\begin{array}{c}0.001^{*} \\
*\end{array}$ & 18.15 & $\approx 0.01$ \\
\hline
\end{tabular}

$X^{2}(1)$ : Compare percentage between pre and immediate phases on implementation. $X^{2}(2)$ : compare percentage between pre and follow up phases of implementation. $(*)$ Statistical significant difference at $<0.05^{*}$-...-.-.- $(* *)$ highly statistical significant difference 
Figure (2): Distribution of total performance score of the studied nurses regarding to care of children with Wilms' tumor at the different phases of program implementation.

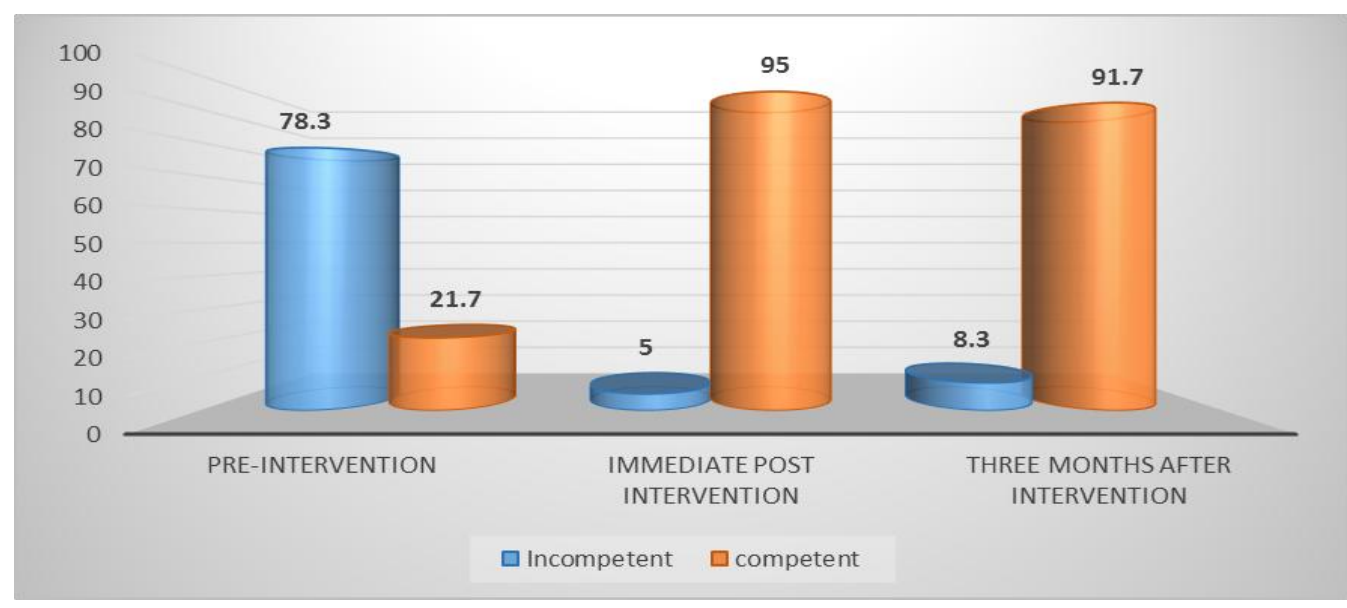

Table (4): Correlation between studied nurses' total knowledge and performance score regarding to Wilms' tumor at different phases of program implementation.

\begin{tabular}{|l|l|l|l|l|l|c|}
\hline Knowledge & \multicolumn{2}{l|}{ Knowledge pre } & \multicolumn{2}{l|}{ Knowledge post } & \multicolumn{2}{l|}{ Knowledge follow } \\
\hline Performance & $\mathbf{r}$ & P value & $\mathbf{r}$ & P value & r & P value \\
\hline $\begin{array}{l}\text { Performance } \\
\text { pre }\end{array}$ & .151 & $>0.05$ & - & - & - & - \\
\hline $\begin{array}{l}\text { Performance } \\
\text { post }\end{array}$ & - & - & .083 & $>0.05$ & - & - \\
\hline $\begin{array}{l}\text { Performance } \\
\text { follow }\end{array}$ & - & - & - & - & .012 & $>0.05$ \\
\hline
\end{tabular}

Table (5): Correlation between studied nurses' total knowledge score and nurses' characteristics at different phases of program implementation.

\begin{tabular}{|l|c|c|c|c|c|c|}
\hline Knowledge & \multicolumn{2}{|c|}{ Knowledge pre } & \multicolumn{2}{c|}{ Knowledge post } & \multicolumn{2}{c|}{ Knowledge follow } \\
\hline $\begin{array}{l}\text { Nurses' } \\
\text { characteristics }\end{array}$ & $\mathbf{r}$ & P value & $\mathbf{r}$ & P value & $\mathbf{r}$ & P value \\
\hline Age & .088 & $>0.05$ & -.023 & $>0.05$ & .121 & $>0.05$ \\
\hline Years of experience & -.032 & $>0.05$ & .046 & $>0.05$ & .131 & $>0.05$ \\
\hline Level of education & -064 & $>0.05$ & -246 & $>0.05$ & -074 & $>0.05$ \\
\hline
\end{tabular}


Table (6): Correlation between studied nurses' total performance score with nurses' characteristics and educational level at different phases of program implementation.

\begin{tabular}{|l|c|c|c|c|c|c|}
\hline Knowledge & \multicolumn{2}{|c|}{ Performance pre } & \multicolumn{2}{c|}{ Performance post } & \multicolumn{2}{c|}{ Performance follow } \\
\hline Nurses' characteristics & $\mathbf{r}$ & P value & $\mathbf{R}$ & P value & R & P value \\
\hline Age & -.018 & $>0.05$ & .181 & $>0.05$ & .135 & $>0.05$ \\
\hline Years of experience & .069 & $>0.05$ & .232 & $>0.05$ & .156 & $>0.05$ \\
\hline Educational level & -.109 & $>0.05$ & .118 & $>0.05$ & .138 & $>0.05$ \\
\hline
\end{tabular}

\section{Discussion}

Wilms' tumor or nephroblastoma is the most common primary renal malignancy of childhood. Worldwide it accounts for $90 \%$ of the pediatric renal tumor which represents $6 \%$ of childhood cancer and it occurs in about 1 out of 200,000 to 250,000 cases and it usually strikes when a child is about 3 years old. Wilms' tumor usually occurs when certain cells in one or both kidneys multiply uncontrollably, growing into a malignant, or cancerous mass (Malkan et al., 2015). The nurse plays a pivotal role in the management of the children with Wilms' tumor. The current study was carried out at Children's Cancer Hospital Egypt (57357) at the Outpatient and Inpatient Pediatric Oncology Settings.

This study is a quasi-experimental to assess the impact of the educational program on nursing care for children suffering from Wilms' tumor.

Regarding to the nurses' characteristics, the present study revealed that the mean age of them was $26.05 \pm 2.16$ years. These finding is supported with the study of Hemdan, (2016) about assessment of nurse's knowledge related to preoperative care provided to the children with oesteosarcoma and their families at
57357, it was found that less than half of the study sample their age ranged between 20-25 years in the recovery room and surgical area and more than one third of them, their age ranged between 20-25 years in the operating room.

According to the level of education of the studied nurses, the results of the current study showed that near to half of the staff nurses had secondary nursing education and bachelors in nursing science. This may due to the fact that, secondary nursing school provides the Egyptian society with a larger number of graduate nurses with diploma degree. These findings in contrast with a study of Bastable and Rushforth (2011), about children management and discharge plan of their child's postoperative pain, they found that most of nurses were qualified from faculties of nursing.

According to years' experience of the studied nurses, the results of the current study showed that more than two thirds of nurses had 1-5 years with mean score $5.78 \pm 4.74$ years of experience in caring for children suffering from cancer. These finding may reflect the importance of raising nurse's knowledge through the continuous educational program to update their knowledge regarding care for children with cancer. These findings came in contrast with Radhika and Ravikiran, (2015), who pointed out that 
most of the staff nurses did not receive basic education regarding care for cancer patients.

It was observed from the result of the current study that, the majority of the study subjects showed highly statistically significant improvement post program implementation in all items of knowledge regarding Wilms' tumor. This finding was supported by the study of Khan et al., (2012), who study assessment of knowledge, skills of oncology nurses, they found that the nurses have poor knowledge and skills.

The present study revealed that the studied nurses' performance regarding port a cath needle insertion was improved after implementation of the educational training program, there was a highly statistically significant difference among studied nurses at pre, immediate post and follow up phases of program implementation. These finding came in the line with the findings of Deshmukh \& Shinde, (2015), in the study under title of the impact of structure education on knowledge and performance regarding venous access device among nurses, they pointed out that the structured education was effective in improving the knowledge and performance of staff nurses regarding venous access device care.

Concerning to the correlations between studied nurses' total knowledge and performance, the present study revealed that there was a positive correlation between total knowledge and performance score at pre, immediate post and follow up phase of program implementation $(\mathrm{P}=>0.05)$. This finding was supported by the study of Geng et al. (2014), who study the role of nurses in the bone tumor in USA, they found that there was a positive correlation between nurse's levels of knowledge and their levels of practice. The researchers believe that good knowledge leads to competent level for practices because nurses can give care with trust. This finding was in accordance with the study of Zhang et al. (2014), who study inhibits growth and induces of oesteosarcoma cells through inhibition of the nuclear factor- $\kappa \mathrm{B}$ pathway, they found that there was the statistically significant difference between health care providers' levels of knowledge and their levels of practice.

As regards to correlation between studied nurses' total knowledge score with age and years of experience at different phases of program implementation, the current study revealed that there was a positive correlation between total knowledge with age and years of experience at the preimplementation phase $(\mathrm{P}=>0.05)$, While in the follow up phase there was a positive association between knowledge score with age and years of experience. This finding agrees with Ahmed, (2014), who study the effectiv of an educational program on mother's knowledge and performance regarding care of their children with thalassemia, who showed that there was the statistically significant difference between parents' knowledge and their age. While there was a highly statistically significant difference between parents' knowledge and their level of education.

As regard correlation between studied nurses' total performance score with age, years of experience and educational level at different phases of program implementation. The result of the current study reveals that there was a positive correlation between total performance and level of education at the pre-implementation phase $(\mathrm{P}=.>0.05)$. While at the immediate post and follow up phases there age was a positive association between performance score age and years of experience and level of education. These findings were 
highly supported by the similar studies of Fahim et al. (2014), who study primary malignant bone tumor in the spine: functional, bioluminescence and histological correlations mentioned that the total knowledge of the health care providers was associated with increase in the years of experiences and level of education.

\section{Conclusion:}

In the light of the study findings, it can be concluded that, the educational program was effective in improving the nurses' knowledge and performance regarding care of children with Wilms' tumor.

\section{Recommendation:}

In the light of the study findings the following recommendations are suggested:

- Newly appointed nurses who are working at oncology unit must be have an orientation program prior to care of children with Wilms' tumor.

- Periodical continuous on jobtraining programs for oncology nurses to update and refresh their knowledge and performance about care of children with Wilms' tumor.

- Regular clinical sessions to monitor the nursing performance at 57357 hospital will reinforce and improve the skills regarding to care of children with Wilms' tumor.

- Further studies and replication of this study in other oncology units.

\section{References:}

Ahmed, (2014): who study effectively of educational program on mothers' knowledge and performance regarding care of their children with thalassemia.

Bastable, A. and Rushforth, H. (2011): Parents' management of their child's postoperative pain, Pediatric Nursing, 17(10): 14-7.

Deshmukh, M., \& Shinde, M. (2015): Impact of structured education on knowledge and practice regarding venous access device care among nurses. International Journal of Science and Research (IJSR), 3(5), 895-901.

Fahim, D. K.; Tatsui, C. E.; Suki, D.; Gumin, J.; Lang, F. F. and Rhines, L. D. (2014): Murine model of a primary malignant bone tumor in the spine: functional, bioluminescence, and histological correlations. Journal of Neurosurgery, 27:1-8; 378-385.

Geng, S.; Zhang, X.; Chen, J.; Liu, X.; Zhang, H.; Zhang, Y.; Bi, Z. and Yang, C. (2014): The tumor suppressor role of mir-124 in osteosarcoma. PLoS One, 9(6): e91566.

Grundy,P., Ritchey, M ., Perlman, J., and Kalapurakal, A., (2010):- Renal Tumors of childhood. In: Kufe DW, Pollock RE, Weischselbaum RR, Bast RC, Gansler TS, Holland JF, Frei E, eds. Cancer Medicine. 6th ed 2010.

Hemdan, T., (2016): Assess nurse's knowledge related to preoperative care provided to the children with oesteosarcoma and their families, Conducted at Children's Cancer Hospital-Egypt, 57357, p.85-91.

Khan, Khurshid Zulfiqar Ali Khowaja2, Tazeen Saeed Ali3 (2012): Assessment of knowledge, skill and attitude of oncology nurses in 
chemotherapy administration in tertiary hospital Pakistan. Open Journal of Nursing, Pp. 97-103.

Malkan, A. D., Loh, A., Bahrami, A., Navid, F., Coleman, J., Green, D. M., Sandoval, J. A. (2015): An approach to renal masses in pediatrics. Pediatrics, 135(1), 142-158.

Oberoi, D. V., White, V., Jefford, M., Giles, G. G., Bolton, D., Davis, I., Harrison, S. (2016): Caregivers' information needs and their 'experiences of care'during treatment are associated with elevated anxiety and depression: a cross-sectional study of the caregivers of renal cancer survivors. Supportive Care in Cancer, $1-10$.

Radhika \& Ravikiran, (2015): Nurses' knowledge and education about oral care of cancer patients undergoing chemotherapy and radiation therapy. avalable at:http://www.ncbi.nlm.nih.gov/pubm ed/?term=Pai\%20RR\%5BAuthor\%5D $\&$ cauthor=true \&cauthor_uid=260096 78 22/6/2016 20:00

Vanderpool, R., Bush, N., CoftaWoerpel, L., \& Wallace, P. (2008): Profiles of 800,000 Users of the National Cancer Institute's Cancer Information Service Since the Debut of Online Assistance.

Zhang, C. L.; Wang, C.; Yan, W. J.; Gao, R.; Li, Y. H. and Zhou, X. H. (2014): growth and induces apoptosis in osteosarcoma cells through inhibition of the nuclear factor- $\mathrm{bb}$ pathway. Oncology Reports, 25-26. 